\title{
Tecnologia da informação, cultura e poder na Polícia Militar: uma análise interpretativa
}

\section{Technology of Information, culture and power in Military Police : an interpreta- tive analysis}

\author{
Maria Cecilia Pereira * \\ Antônio Claret dos Santos* \\ Mozar José de Brito ${ }^{* * *}$
}

\section{Resumo}

No ambiente competitivo, a tecnologia da informação (TI) emerge como elemento essencial para o êxito organizacional. Tal processo não deve ser encarado apenas como "adaptação" das estruturas internas das organizações ao ambiente, pois atinge elementos mais complexos, como os valores, a cultura e as relações de poder nas organizações. Nesse contexto, este artigo, considerando a tecnologia da informação como elemento de inovação tecnológica, tem por objetivo analisar as relações entre o uso dessa tecnologia, a cultura e as relações de poder numa organização de caráter militar. Para isso, inicialmente, são apresentadas algumas considerações a respeito da TI e dos processos de formação da cultura e do poder nas organizações. As análises contribuiram para compreender as relações entre a TI, a cultura e as relações de poder, por meio de significados compartilhados e expressados, principalmente, através de símbolos, rituais e mitos. As relações de poder apresentaram mudanças no sentido das responsabilidades distribuidas, das interações comunicativas e da hierarquia (informal). Quanto à cultura, esta sinaliza para valores compartilhados em termos de inovação e flexibilidade.

Palavras-chave: tecnologia da informação; cultura; poder; mudança organizacional.

\begin{abstract}
In the competitive environment, Information Technology (IT) emerges as an essential element to organizational success. It involves more complex elements, such as values, culture and power relations in the organizations. Considering information technology as an element of technological innovation, this paper aims to analyze the relationship between information technology implementation, culture and power relations in a military organization. Initially, some considerations regarding it and the process of culture formation and power establishing in the organizations are presented. The analyses have contributed for understanding the impact of it on culture and power relations through shared and expressed meanings, mainly, in terms of symbols, rituals and myths. Power relations were changed towards sharing responsibilities, communicative interactions and hierarchy (informal). Concerning culture, it aims at shared values in terms of innovation and flexibility.
\end{abstract}

Key-words: information technology; culture; power; organizational change.

\section{Introdução}

As organizações estão inseridas em um ambiente global, competitivo, cada vez mais interligado, porém, mais complexo e diversificado. Nesse ambiente, a tecnologia da informação emerge como elemento essencial para que se consiga o êxito organizacional. A dinâmica de adoção e uso de tecnologia da informação impulsiona um processo de mudança organizacional. Tal processo não deve ser encarado de maneira funcionalista ou unilate-

- Doutoranda em Administração do Programa de Pós-Graduação em Administração da Universidade Federal de Lavras - PPGAD/UFLA. Endereço: Rua João Laurente, 175, Cruzeiro do Sul, Lavras, Minas Gerais, Brasil - CEP: 37200-000. E-mail: cecilia@navinet.com.br.

" Mestre em Administração pela UFLA e Capitão da PM-MG. Endereço: PPGAD/UFLA Caixa Postal 37 - Lavras - MG. CEP 37.200.000. E-mail:claret@ufla.br .

- Doutor em Administração pela Universidade de São Paulo. Professor do Departamento de Administração e Economia da Universidade Federal de Lavras...

Endereço: PPGAD/UFLA Caixa Postal 37 - Lavras - MG. CEP 37.200.000 E-mail: mozarjdb@ufla.br 
ral, apenas como "adaptação" das estruturas internas das organizações ao ambiente, pois ele atinge elementos mais complexos, como os valores, a cultura e as relações de poder nas organizações.

Nesse contexto, este artigo - considerando a tecnologia da informação como elemento de inovação tecnológica - tem por objetivo analisar as relações entre o uso dessa tecnologia, a cultura e as relações de poder numa organização de caráter militar. O componente de tecnologia da informação, elemento específico de análise deste estudo, é o Portal Corporativo da $6^{\mathrm{a}}$ Região de Polícia Militar do Estado de Minas Gerais, da qual faz parte a organização especificamente analisada, o $8^{\underline{0}}$ Batalhão da Polícia Militar, sediado na cidade de Lavras, no sul daquele estado.

O portal foi colocado à disposição dos policiais militares da região sul de Minas Gerais a partir de 2003, viabilizando, além do acesso à Internet, a operacionalização de serviços como: sala de reuniões (bate-papo), quadro de avisos, cursos especiais, informações operacionais, visualização e análise de efetivo local, troca de e-mails e fórum de discussões. Os serviços disponibilizados possibilitam "relações diretas" entre policiais dos mais diversos níveis, além do acesso direto aos comandos locais e regionais.

Portanto, tem-se como elemento de estudo, um ambiente informacional altamente inovador, capaz de interligar processos estruturais, sociais e cognitivos dos atores organizacionais. A expectativa é de que este estudo permita compreender como a utilização do Portal Corporativo pode influenciar na cultura organizacional e nas relações de poder por meio dos significados construídos e compartilhados entre os atores sociais, durante o processo de mudança. Assim, a dimensão privilegiada é a subjetividade dos atores organizacionais.

\section{As organizações e a tecnologia da informação}

A exigência de flexibilidade e de uma melhor interação entre os membros organizacionais é consequiência de mudanças desencadeadas pelo mercado, principalmente, a partir da década de 1970, quando se acirrou a concorrência entre as organizações. Com isso, a produção em massa de produtos padronizados deixou de ser interessante e a competição entre as organizações passou a se dar pela flexibilidade para diversificar os produtos (sem encarecê-los) e pelo atendimento rápido (antes da concorrência) aos clientes externos e internos (membros da organização). Em grande parte, essa flexibilidade foi conseguida pela reestruturação de processos produtivos e com novas formas de gerenciamento, incluindo-se aí a adoção de inovações tecnológicas voltadas para os diversos setores da organização.

O conceito de inovação, propriamente dito, não pode desvincular-se do conceito de inovação tecnológica. Este tem sido bastante discutido e reconhecido, principalmente, no que tange ao contexto empresarial. Para as empresas, a inovação pode ser entendida como a capacidade delas se manterem lucrativas (seja pelo aumento do valor percebido pelo cliente, pela redução de custo, ou ainda por ambos) de modo sustentável. Para Schumpeter (1975) e (1982), inovação é a aplicação comercial ou industrial de alguma coisa nova (de um novo produto, processo ou método de produção), é um novo mercado (ou fonte de suprimentos) ou uma nova forma de organização de negócios (comercial ou financeira).

Drucker (1986) define inovação como a ferramenta dos empreendedores, o meio pelo qual exploram as mudanças como uma oportunidade para oferecer um novo produto ou serviço. $\mathrm{O}$ exame de inovações em diversas empresas européias e norte americanas propiciou a definição de inovação como uma nova forma de romper barreiras definidas no setor pelos conceitos de vantagens competitivas, criando soluções diferenciadas a baixo custo. Assim, o conceito de inovação tecnológica está intimamente relacionado ao aumento ou manutenção da competitividade. Dessa forma, a inovação tecnológica pode ser entendida como toda modificação na cadeia de valor da organização, extrapolando a associação exclusiva com processos ou produtos, e que afeta, de forma significativa, a vantagem competitiva da empresa ou a estrutura industrial na qual ela está inserida. De forma complementar e sintética, a transformação tecnológica pode ser definida como tecnologia aplicada à cadeia de valor voltada para o aumento ou manutenção da competitividade (PORTER, 1989).

Dessa perspectiva, a tecnologia da informação (TI) pode ser tratada como uma inovação tecnológica, na medida em que permeia as cadeias de valor, mudando a forma de executar as atividades de valor e também a natureza 
das ligações entre elas. Ao fazer isso, a TI pode afetar a competição das empresas, modificando os relacionamentos entre clientes, fornecedores e concorrentes (PORTER, 1989).

Entretanto, o ponto de interesse neste constructo é a relação entre o uso da TI, a cultura e as relações de poder entre os atores organizacionais. É um enfoque que não está distante do enfoque da competitividade, visto que uma das formas de mantê-la é otimizando o fluxo de informação entre os membros organizacionais e, conseqüentemente, o relacionamento entre eles. Esse processo pode ser impulsionado pela implementação da TI. Para Stoner (1999), somente com informações precisas e na hora certa, os administradores podem monitorar o progresso na direção de seus objetivos e transformar os planos em realidade.

A TI é uma ferramenta utilizada nas organizações com a finalidade principal de prover serviços e canais de comunicação. Geralmente, essa tecnologia opera sob sistemas computacionais. Nos primeiros estágios do uso de computadores nas empresas, a capacidade limitada de hardware e software restringia, de forma bastante intensa, as possibilidades de aplicações da TI. Assim, apenas aplicações mais estruturadas e menos complexas podiam ser implementadas como, por exemplo, folha de pagamento, controle de estoque e contas a pagar. Com o desenvolvimento tecnológico, o leque de possibilidades foi ampliado e uma gama de novas alternativas de aplicações da TI tornou-se possível (LAURINDO et al, 2001). Dos benefícios que a TI proporciona às organizações, podem ser citados o fato de dar subsídios aos gestores para a elaboração de estratégias empresariais, a facilidade e rapidez que proporciona no desenvolvimento de atividades burocráticas, a gestão dos meios de produção e dos negócios, a melhoria e agilidade nos processos de comunicação interna e externa das organizações; sem contar a melhoria do relacionamento entre os membros organizacionais (PRATES e OSPINA, 2004).

Diferentes aplicações da TI - conforme sua natureza, abrangência e grau de modificação impostos - apresentam diferentes formas de interação com a cultura e as relações de poder numa organização (FLEURY e FLEURY, 1995). Portanto, trata-se de um processo profundo de mudança que não só abrange o ambiente tecnológico, mas também o ambiente técnico, as pessoas, a cultura e toda a estrutura da empresa; por isso é preciso que os atores sociais estejam envolvidos com o processo de adoção da TI. Nesse sentido, alguns autores (MUNFORD, 1988; SEGRE e XEXEO, 1995) afirmam que as organizações não estão se preparando adequadamente para a adoção de inovações tecnológicas como a TI.. Uma metodologia que enfatize uma gestão mais humana da implementação dessa tecnologia - visando elementos como a cultura e as relações de poder - pode minimizar tais reações.

\section{Cultura e poder no espaço organizacional}

Como realidade socialmente construída, a organização torna-se apenas uma referência para direcionar comportamentos individuais. Qualquer processo de mudança - nesse caso, a adoção da TI - pode desencadear reações adversas que influenciam os próprios valores, crenças e interpretações compartilhadas pelos agentes envolvidos no processo. Tais elementos são constitutivos da cultura organizacional.

O conceito de cultura tem sua gênese na antropologia, mas é também explorado pela sociologia e pela psicologia. Em termos organizacionais, as referências à cultura estão presentes desde os anos 1950. Entretanto, somente a partir da década de 1980, o tema "cultura" passou a receber maior atenção dos estudiosos de administração, quando começaram os estudos e publicações sobre suas implicações para as empresas. Freitas (1991) assinala que o fator predominante para essa preocupação foi o crescente desempenho tecnológico e econômico do Japão, atribuído, principalmente, à sua formação cultural.

Na teoria organizacional, o debate sobre cultura apresenta várias perspectivas. De forma resumida, podem ser citadas duas delas: a funcionalista e a simbólico-interpretativa. Cada uma contém o paradigma que rege a visão e o conceito de cultura, propriamente dito. A corrente funcionalista é a corrente predominante (main stream) nos estudos organizacionais (AKTOUF, 1993). Ela considera que a empresa pode "ter ou ser" uma cultura, e que essa cultura pode ser ou não eficiente e bem-sucedida. Além disso, da perspectiva funcionalista, a cultura é atrelada à função que denota para a organização. Por essa ótica, a cultura organizacional é o padrão de premissas básicas inventado por um grupo no processo de aprendizagem de como resolver seus problemas de adaptação externa e de integração interna. Nesse sentido, a cultura organizacional é "diagnosticável", reconhecível, e pode, com certos cuidados, ser manipulada (SCHEIN, 1996). 
De acordo com a abordagem interpretativa, a cultura não pode ser entendida simplesmente como objeto ou artefato que se pode manipular, pelo menos, em todos os seus aspectos. Dessa perspectiva, a cultura é composta de padrões socialmente estabelecidos e aceitos, formados no decorrer da convivência entre os sujeitos sociais, podendo constituir estruturas inconscientes, sistemas de conhecimento e de percepção ou, ainda, símbolos e significados compartilhados (MARTIN, 1992; GEERTZ, 1989; SCHUTZ, 1979).

Sob essa ótica, privilegia-se a dimensão simbólica da organização como expressão singular da realidade. O paradigma simbólico assume que o ser humano define e cria sua própria realidade e, conseqüentemente, a realidade da organização. A construção social da realidade deriva da criação coletiva dos sentidos e significados atribuídos pelos membros da organização a uma determinada ação ou objeto. Dessa forma, os atores sociais podem desenvolver definições compartilhadas da realidade organizacional (SCHULTZ, 1994).

Para Freitas (1991), a definição da realidade e a objetivação da cultura, ou sua efetiva concretização, dá-se por meio de seus elementos. Isso fornece aos membros da organização o direcionamento para os relacionamentos intra-organizacionais. A assimilação desses elementos é efetuada pela linguagem que lhe dá um caráter concreto, necessário para o repasse entre os indivíduos e para a aceitação do modo como foram expostos. Tais elementos, são descritos por Schultz (1994) como símbolos-chave expressados por rituais, mitos, estórias e cerimônias.

Nesse contexto, emergem a existência das relações entre diferentes símbolos e a comunicação entre os processos como importantes fatores para manter a realidade simbólica compartilhada e transmitir a "teia dos significados" entre as generalizações organizacionais. Portanto, cultura organizacional consiste, principalmente, da socialização dos membros da organização definindo realidades como reflexo do "estilo organizacional" (SCHULTZ, 1994).

A interpretação dos símbolos pode ser guiada pela visão de mundo (imagem mental da realidade), pelos valores (visão da estética e da moral), pelas metáforas e pelas metonímias (parte que pode representar o todo). As metáforas e as metonímias são artifícios usados pelos membros da organização para ilustrar o caminho cultural. São utilizadas para interpretar e formular representações visuais da cultura organizacional (SCHULTZ, 1994). Neste constructo, admite-se que o processo de adoção da TI é construído e mantido na mente dos membros organizacionais, os quais, por meio de interpretações de rituais, mitos e outros símbolos, compartilham os significados e contribuem para a interpretação da realidade organizacional. Isso significa que a TI pode relacionar-se com o processo de construção da cultura organizacional - à medida que age como elemento de comunicação e consenso - bem como expressar a instrumentalização das relações de poder. Por sua vez, as relações de poder podem ser sustentadas pelas ideologias e por uma ordem moral que os indivíduos visualizam e experimentam como legítimas, através de rituais, mitos e símbolos culturais. Ao implantar um elemento de mudança (a TI), a organização precisa legitimar a nova ordem, o que pode influenciar as relações entre os atores sociais e os grupos. Isso significa que o fenômeno da adoção de uma nova tecnologia pode contribuir para mudanças nas estruturas de poder em uma organização.

Vários autores têm contribuído para os estudos sobre o poder nas organizações (mesmo que o foco de suas pesquisas seja o sociológico). Mais tradicionalmente, podem ser citados os estudos de Marx (1976) e Weber (1978), os quais enfocam a existência de conflitos de interesses e tratam o poder como uma forma de dominação. Nesse sentido, os autores mostram como o poder penetra nas estruturas organizacionais para servir a alguns, mas não a todos os grupos de interesses. No campo dos estudos organizacionais, o poder geralmente refere-se à estrutura hierárquica dos cargos e às relações recíprocas, por meio das estruturas formais e burocráticas (THOMPSON, 1956).

Ambas as correntes mencionadas desenvolveram concepções mais funcionalistas do poder. O desenvolvimento de um campo mais crítico dessa temática tenta reinterpretar, por meio de práticas disciplinares, as regras que construíram a burocracia, além de analisar o poder por um prisma mais micro, ou seja, por meio das relações entre os atores organizacionais (FOUCAULT, 1977).

Nesse sentido, pode-se elevar o foco para as formas como os agentes utilizam suas estratégias de poder e, dessa forma, compreender o poder e suas relações num processo de mudança contínua. Para os estudos organizacionais, isso implica considerar a influência das relações culturais, políticas e econômicas na ação dos membros 
nas organizações; ou seja, compreender o poder em sua dinâmica e não apenas em suas manifestações estruturais (hierarquias etc.), admitindo seus movimentos relacionais construídos por meio de práticas discursivas e implícitas de controle negociado. Para Hardy e Clegg (2001, p.275), na perspectiva crítica, o

poder não é mais apenas um recurso conveniente, manipulável e determinístico. Ao contrário, todos os atores operam dentro de uma estrutura de dominação - uma rede dominante de relações de poder - dentro da qual as perspectivas de saída eram limitadas tanto para os grupos dominantes quanto para os grupos subordinados. [...] A resistência é algo positivo: uma oportunidade para a ação humana criativa, particularmente, quando associada às categorias subjugadas, tais como trabalhadores, mulheres e minorias étnicas, como uma reafirmação contra os processos de dominação.

A organização passa a ser considerada como um espaço de elaboração e negociação de princípios, envolvendo os processos de articulação de interesses entre os membros organizacionais. Cada ator organizacional pretende reforçar seu interesse e legitimar sua ação para garantir seu espaço e posição na estrutura organizacional. Surgem questionamentos e contestações que podem ser observados nas relações patrão/empregado, entre grupos, e até mesmo nas relações de gênero. Tais movimentos evoluem e se transformam sob várias formas de controle organizacional e suas relações com a cultura e liderança.

Nesse sentido, o poder não envolve, necessariamente, a tomada de determinada posição, a identificação de quem possui mais ou menos poder, mas sim a busca da descrição de seu papel estratégico - como ele é usado para transformar as pessoas em personagens que articulam um jogo de moralidade organizacional (HARDY e CLEGG, 2001).

No contexto da adoção da TI, estudar as relações de poder justifica-se pelas possíveis implicações decorrentes dessa incorporação da TI na distribuição de responsabilidades, na hierarquia e nas crenças já legitimadas no espaço organizacional. Observa-se uma dificuldade por parte dos atores organizacionais de "aceitar" as novas tecnologias, em grande parte, pelas mudanças ocasionadas nas estruturas de poder (BORNSTEIN e VILLELA, 1992).

\section{Delineamento metodológico da pesquisa e proposta de análise}

Nesta pesquisa, destaca-se a utilização do paradigma interpretativo de análise (ALENCAR, 1999). Esse enfoque visa à análise das interpretações da realidade, privilegiando a percepção do indivíduo sobre os fenômenos analisados. Para tanto, desenvolveu-se um estudo de caso (MURRAY, 1974) no 8ํㅡㅁ Batalhão da Polícia Militar de Lavras (MG). O estudo de caso permite aprofundar a análise de um fenômeno por trabalhar com cenários específicos. Dessa forma, o estudo de caso vincula-se ao paradigma interpretativo, pois possibilita compreender os significados que os indivíduos atribuem às suas ações e às ações de outros em determinado ambiente ou situação (ALENCAR, 1999).

Dessa perspectiva de análise, adotou-se o método da triangulação de dados, o qual procurar utilizar dados originários de várias fontes num mesmo estudo, com a finalidade de se conseguir uma ampla descrição, explicação e compreensão do objeto em foco no estudo (TRIVIÑOS, 1987). Para tanto, foram definidas duas etapas básicas para a coleta de dados:

- pesquisa bibliográfica e análise documental - mais precisamente sobre a implementação do Portal Corporativo da $6^{\mathrm{a}}$ Região da Polícia Militar de Minas Gerais (6 $\left.{ }^{\mathrm{a}} \mathrm{RPM}\right)$. Nessa fase, pretendeu-se conhecer como a TI foi implementada na organização, bem como traçar um breve perfil da mesma;

- entrevistas com membros da organização e observação não participante. No caso das entrevistas, a amostra foi intencional, e o instrumento de coleta de dados foi um questionário não-estruturado, aplicado a 13 policiais militares envolvidos com a implementação ou utilização do Portal Corporativo. Nessa etapa, o objetivo foi mapear a influência do uso da TI na cultura e nas relações de poder no espaço simbólico da organização. 
Para compreender como a utilização da TI pode estar relacionada com a cultura e as relações de poder em uma organização, delineou-se uma proposta teórica para análise (figura 1), a partir dos principais conceitos apresentados anteriormente, considerando-se o recorte epistemológico adotado na pesquisa.

Figura 1

Proposta teórica de análise

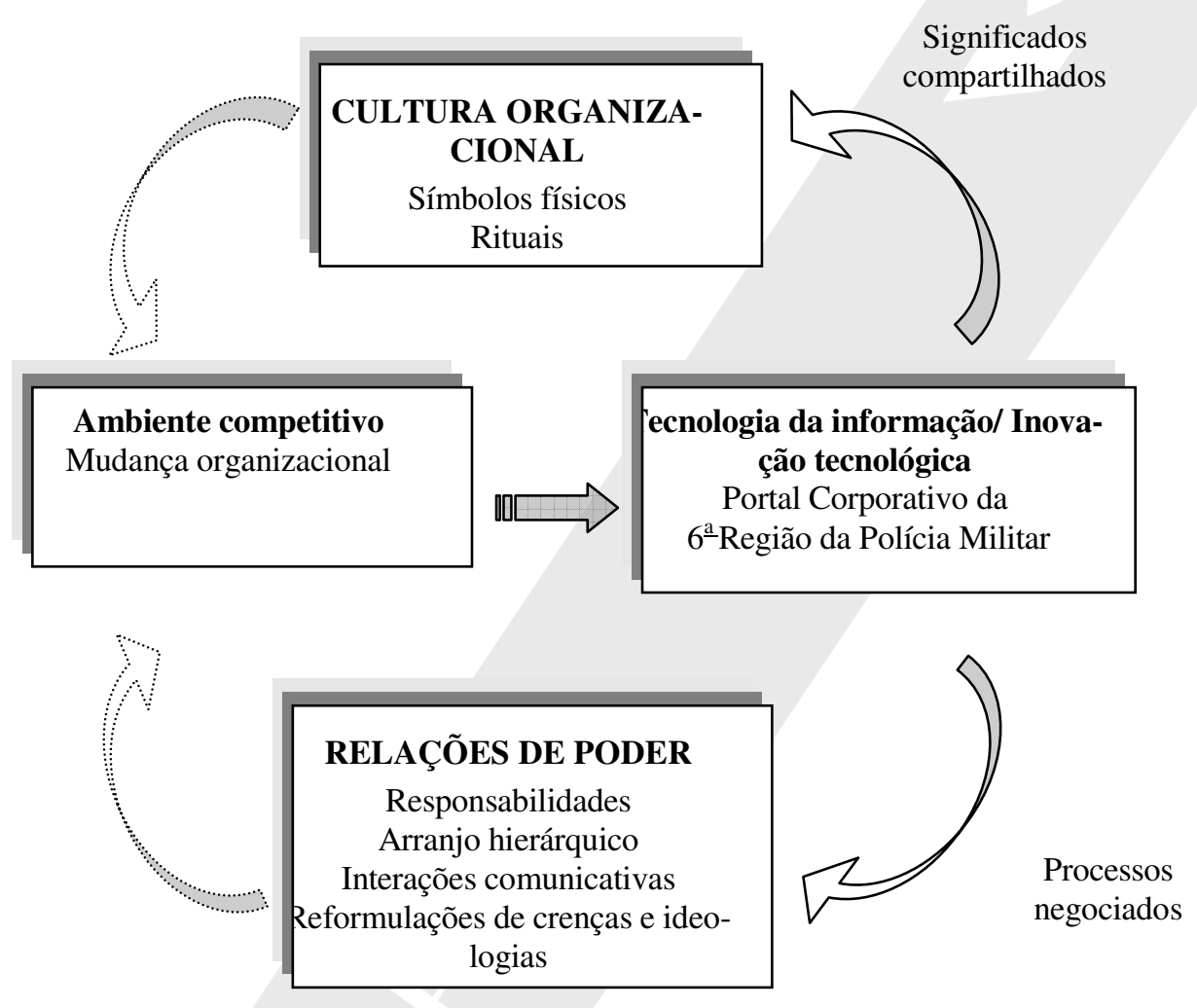

Fonte: elaborado pelos autores.

Dessa forma, a definição operacional das categorias de análise pode ser descrita como:

- tecnologia da informação - foi considerada uma inovação tecnológica, à medida que interfere na cadeia de valor da organização em prol de sua competitividade. Essa ferramenta, ao lançar novos canais de comunicação, formas de gestão de produtos e serviços, além de novas formas de relacionamento entre os atores organizacionais, pode influenciar na construção da cultura e nas relações de poder em uma organização. Neste estudo, a TI analisada é o Portal Corporativo da $6^{\mathrm{a}}$ RPM;

- cultura - pode ser construída por meio dos significados internalizados e compartilhados entre os atores organizacionais. Os significados são construídos pela interpretação dos indivíduos com base em símbolos físicos, rituais e mitos. Os símbolos físicos considerados nas análises, foram, além dos próprios símbolos materiais presentes na cultura militar, os documentos, jornais e o próprio conteúdo do Portal Corporativo. Os rituais analisados foram, basicamente, as etapas de implementação do portal, os treinamentos e as atividades viabilizadas por este. Além dos rituais relativos especificamente ao processo de implementação do Portal Corporativo, também foram considerados os rituais militares, de uma maneira geral. Os mitos foram operacionalizados pela identificação de histórias que condizem com valores e crenças da organização, e por meio de narrativas referentes à implementação e utilização do Portal Corporativo; 
- relações de poder - o poder foi considerado um fenômeno relacional, presente nos discursos e objeto de negociação entre os membros organizacionais. Foram observadas as relações que envolvem a distribuição de responsabilidades, o arranjo hierárquico, as interações comunicativas e a reformulação de crenças e ideologias no processo de adoção da TI.

Com base na proposta de análise e na descrição das categorias, apresentam-se as seguintes questões de pesquisa:

- como foi o processo de implementação do Portal Corporativo da $6^{\mathrm{a} R P M}$ ?

- quais foram as principais influências dessa ferramenta na cultura e nas relações de poder na organização?

Vale ressaltar que a análise dos dados coletados ocorreu sob o paradigma interpretativo, por meio da pesquisa qualitativa, conforme a proposta de Triviños (1987).

\section{Aspectos da organização, do Portal Corporativo e de sua implementação}

Para responder às questões de pesquisa, é necessário conhecer as principais características da organização em estudo, tendo em vista que esse processo é fundamental para se desvendar os aspectos simbólicos que a permeiam.

A organização em estudo é composta pelo $8^{\circ}$ Batalhão da Polícia Militar ( $8^{\circ}$ BPM) e pela administração da $6^{\mathrm{a}}$ Região da PM de Minas Gerais. O $8^{\mathrm{o}}$ BPM foi instalado, provisoriamente, em Belo Horizonte, em 11-7-1932, sob o comando do tenente-coronel Fulgêncio de Souza Santos e a denominação de $8^{0}$ Batalhão de Infantaria. Sua instalação ocorreu quando da eclosão do Movimento Revolucionário Paulista, visto que em 1931, já havia sido sancionado o Decreto $\mathrm{n}^{\circ} 10.068$, que transformava o Grupo de Metralhadoras Pesadas da Força Pública em $8^{\circ}$ Batalhão de Infantaria. A escolha da sede definitiva do $8^{\circ}$ BPM ocorreu em 1934 e a cidade escolhida foi Lavras, localizada no sul de Minas Gerais e considerada, na época, um importante terminal ferroviário.

A área de atuação é dividida em cinco subunidades de execução operacional. Destacam-se como principais centros urbanos as cidades de Lavras, Oliveira, Andrelândia e Campo Belo. Em sua ação operacional, o 8 BPM faz o policiamento ostensivo em 37 municípios e dois distritos. A organização em estudo tem como missão cuidar da segurança pública, atuando preventiva e repressivamente em diversas operações, como a Operação Fronteira, de cerco e bloqueio, desmanche e blitz, levando-se em conta sempre os princípios de universalidade, responsabilidade e o compromisso com os resultados.

Em 1986, foi criado o Comando de Policiamento de Área 6, com sede em Lavras, que hoje é a 6 ${ }^{\mathrm{a}}$ Região da PM, responsável pelo policiamento no sul de Minas, região que pelo vertiginoso crescimento industrial que tem apresentado, é uma das que mais se desenvolvem no estado. A $6^{\mathrm{a}}$ RPM compreende os seguintes batalhões de polícia: o $8^{\circ} \mathrm{BPM}$, o $20^{\circ} \mathrm{BPM}$, o $24^{\circ} \mathrm{BPM}$ e o $29^{\circ} \mathrm{BPM}$. Atualmente, a $6^{\mathrm{a}} \mathrm{RPM}$ tem sua estrutura subdividida em seis seções: a de Recursos Humanos, de Logística, de Inteligência, a Secretaria, a seção de Comunicação Organizacional e a de Planejamento de Operações.

A organização militar é caracterizada por estar encarregada de uma missão definida e dispor de uma estrutura interna (tanto hierárquica quanto de processos) legitimada entre os membros organizacionais (policiais militares) e a sociedade em geral. Tal característica, a despeito de sua condição indispensável para o pleno funcionamento das atividades militares, pode, na maioria das vezes, funcionar como um fator "limitante" para a inovação e evolução dos processos organizacionais (administrativos e operacionais). O estudo de Brito e Brito (1996) demonstra que o próprio processo de socialização dos atores organizacionais passa por um processo formal, rígido, marcado por vários rituais, com a finalidade de internalizar as normas, valores e comportamentos apropriados à cultura militar. Ou seja, despojar o civil e vestir o militar.

Esses fatores sinalizam para uma cultura que, ao mesmo tempo em que fortalece e unifica os valores da organização, pode dificultar processos de mudança e inovação. No entanto, ao analisar particularmente a realidade da 
$6^{a} \mathrm{RPM}$, observou-se - principalmente entre os policiais do setor administrativo - uma predisposição em aceitar os processos de mudança e a reconhecer sua importância. Esse fato pode ser reforçado pelo seguinte discurso:

É preciso fazer surgir o novo, sejam processos e produtos, mesmo que isso acarrete a morte do velho enquanto ainda é lucrativo. É preciso romper com as velhas práticas, já que o futuro será bem diferente do passado e do presente. Schumpeter, famoso precursor da Teoria do Desenvolvimento Capitalista, cunhou uma expressão que retrata bem este fato: "destruição criativa" (trecho de um discurso cujo texto está disponível na página do Portal Corporativo da $\left.\sigma^{\underline{a}} R P M\right)$.

Observa-se que há quem veja a organização militar como uma organização que também precisa traçar "estratégias" para sobreviver e manter sua "competitividade". Só a partir desse entendimento é que uma organização desse tipo pode estar preparada para o processo de mudança, principalmente, no que se refere às mudanças tecnológicas que podem influenciar nos processos administrativos, culturais e nas relações de poder. Nesse contexto, a $6^{\mathrm{a}}$ RPM - em parceria com a Fundação de Amparo à Pesquisa e Extensão de Minas Gerais (Fapemig) e a Universidade Federal de Lavras (UFLA) - desenvolveu o Núcleo de Desenvolvimento de Projetos (NDP) - formado por professores e alunos do Departamento de Ciência da Computação da UFLA e militares da $6^{\underline{a}}$ RPM -, com objetivo principal de desenvolver e pesquisar novas tecnologias, aplicáveis a segurança pública.

Dentre os principais projetos desenvolvidos pelo NDP estão o Projeto de Computação Móvel, o Sistema de Vídeovigilância, o de Interpretação e Análise Geoespacial e o Portal Corporativo, foco desta análise. A maioria dos projetos recorre à TI como ferramenta para sua efetivação. Para a adoção bem sucedida da TI é preciso que os membros organizacionais estejam envolvidos e comprometidos com o processo, e que reconheçam a importância do mesmo para a sua função e para a organização em geral. Assim, foram disseminados alguns conceitos sobre TI entre os policiais, no próprio Portal Corporativo, antes mesmo de se iniciar o processo de implementação. Analisou-se alguns desses conceitos disponibilizados via Portal Corporativo:

A tecnologia da informação é um conceito amplamente utilizado na administração moderna de uma empresa. Como tecnologia da informação tem-se todos os produtos (de informática ou não) que permitem a manipulação e o uso da informação, apoiando os trabalhos operacionais com a maior eficiência e menor custo possíveis.[...] A aceitação das tecnologias de informação como recurso para a construção socialhistórica da sociedade fornece novos caminhos para a apropriação do conhecimento aplicável nas mais diversas áreas, inclusive, na segurança pública, como ferramenta de combate à criminalidade urbana (trecho de um discurso cujo texto está disponível na página do Portal Corporativo da $6^{\underline{a}} R P M$ ).

Em um primeiro momento, ressalta-se que a moderna administração recorre amplamente à TI; ou seja, para que a organização acompanhe a evolução administrativa, deve estar familiarizada com o conceito e a prática da TI. $\mathrm{O}$ veículo que permite a viabilização da TI advém da informática. Portanto, subentende-se que os membros organizacionais devem estar cientes da importância de adquirir conhecimentos em informática. Concomitantemente, evidencia-se a importância da TI como facilitadora do trabalho operacional e da relação com a sociedade, à medida que o conhecimento e a inovação tecnológica são utilizados em prol de serviços mais eficientes para a comunidade.

Essa gama de informação, repassada para os atores organizacionais, objetiva a conscientização dos mesmos sobre a importância da implementação e utilização da TI nos processos da organização. Esse fato indica a fase de preparação para a mudança, uma tentativa de amenizar prováveis impactos no âmbito da cultura e das relações de poder.

Especificamente, com relação ao Portal Corporativo, divulgou-se entre os membros organizacionais a seguinte concepção:

Os portais corporativos oferecem uma grande capacidade para que as organizações embarquem em transformações significativas, remodelando e alinhando seus objetivos e motivações. Se forem devidamente implementados e apoiados por transformações gerenciais que fomentem confiança, os portais cor- 
porativos podem também estabelecer a base e o ambiente para o desenvolvimento de relacionamentos; isso traria conseqüências nos ciclos de inovação, no ambiente de aprendizado, no atendimento ao cliente e, finalmente, numa maior economia de recursos materiais e humanos (trecho de um discurso cujo texto está disponível na página do Portal Corporativo da $\left.6^{\underline{a}} R P M\right)$.

Reafirmando que para o funcionamento de qualidade é necessário o envolvimento dos usuários, delega-se também aos próprios policiais militares a responsabilidade de fazerem valer o projeto, o qual deve alcançar dimensões gerenciais. Ao sinalizar para as mudanças gerenciais, o discurso chama a atenção para as mudanças "relacionais", as quais envolvem aspectos culturais, de aprendizagem e de poder.

Levando em conta as concepções difundidas e compartilhadas acerca da importância da utilização do Portal Corporativo para a otimização dos processos operacionais e gerenciais da Polícia Militar, o mesmo foi implementado na $6^{\mathrm{a}} \mathrm{RPM}$, está em pleno funcionamento e em constante processo de melhoria.

O projeto foi desenvolvido por um capitão da $6^{\mathrm{a}} \mathrm{RPM}$, em parceria com alunos da UFLA, e disponibilizado aos policiais militares da região sul de Minas Gerais, que utilizam desde o ano de 2003, viabilizando não apenas o acesso à Internet, mas também a operacionalização de serviços como: sala de reuniões, quadro de avisos, cursos especiais, informações operacionais, visualização e análise de efetivo local, troca de e-mails e fórum de discussões, que adiante serão descritos com maiores detalhes.

Segundo depoimento prestado por um capitão da $6^{a}$ RPM, a necessidade surgiu, num primeiro momento, pelas precárias condições de repasse das ocorrências aos policiais militares. Os policiais militares, ao iniciarem suas funções, devem estar cientes dos principais fatos ocorridos (em termos de criminalidade) na região em que atuam. Tais informações eram repassadas via fax para um policial responsável, o qual fazia a leitura do material e selecionava as principais ocorrências. Posteriormente, o repasse era feito aos demais policiais que se preparavam para o trabalho. Esse procedimento, a rigor, deveria ser diário. Entretanto, muitas informações acabavam desviadas, ou não havia tempo suficiente para o repasse de todas. A Internet surgiu como um importante veículo para o repasse dessas informações, com conteúdo e tempo otimizados.

O projeto avançou para a criação de um portal que, além da disponibilização das ocorrências, também proporciona vários outros tipos de serviços. Dessa forma, o objetivo postulado para o Portal Corporativo é:

O de criar uma rede de inteligência para prover de forma fácil e rápida o acesso a dados, informações e conhecimentos relevantes para a realização das funções presentes na organização, e ainda criar melhores meios de comunicação que interconectarão todos os membros da organização. É esperado que o Portal Corporativo da $6^{a} R P M$ fomente a criação, gerenciamento e compartilhamento de conhecimento, tanto individual como coletivo, que incentive os membros da organização a aprender, a criar, a inovar e a ter idéias por si só. O portal visa também atender ao público em geral, através de serviços como o Net - Denúncias e o Fale Conosco, além de disponibilizar dicas e informações como eventos, concursos e projetos. (texto extraído do Portal Corporativo da $\sigma^{\underline{a}} R P M$ )

Uma vez definido o objetivo do Portal Corporativo, fica claro o alcance esperado do projeto e, conseqüentemente, as possíveis relações deste com o espaço simbólico da organização. Deve ser ressaltado que a dimensão privilegiada neste estudo não centra seu interesse no conteúdo formal das relações ou da utilização do Portal Corporativo, e sim na subjetividade dos policiais. Uma vez definido o enfoque para que possa ser identificada a dimensão subjetiva das relações entre o uso da TI, a cultura e nas relações de poder - torna-se necessária uma descrição mais detalhada do Portal Corporativo e seu processo de implementação, mais especificamente na $6^{\mathbf{a}}$ RPM.

Para facilitar as operações e diminuir o risco de apropriação indevida de informação por parte de pessoas nãoautorizadas, foi desenvolvido um portal dividido em quatro níveis, conforme mostra a figura 2 : 


\section{Figura 2}

Níveis do Portal Corporativo da $6^{\underline{a}}$ Região da Polícia Militar (MG)

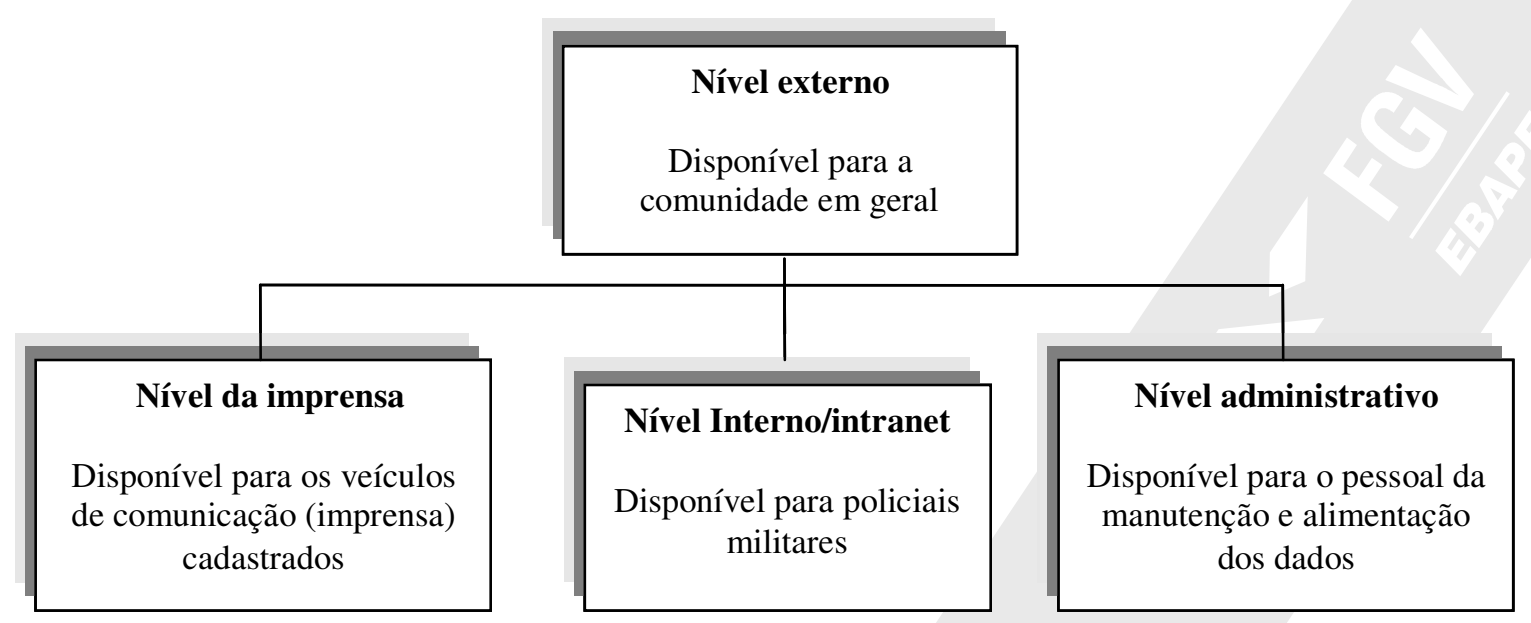

Fonte: elaborado com base nos dados da pesquisa.

- nível externo - disponível para o público geral, por meio do endereço eletrônico <www.pmmg.6rpm.mg.gov.br>. O principal objetivo nesse nível é a maior interação dos policiais militares com a comunidade. Os serviços oferecidos são:

1. registro das principais ocorrências na região;

2. possibilitar a realização de enquetes a respeito do trabalho da Polícia Militar;

3. dar dicas à população sobre segurança;

4. disponibilização de alguns links, e-mails e telefones de interesse;

5. "fale conosco", que possibilita um canal direto para que a comunidade apresente sugestões e dúvidas a respeito do trabalho da PM;

6. "Canal de Denúncias", onde com garantia de anonimato a quem o procura;

7. "Espaço Cultura", que divulga datas, eventos e textos de interesse;

8. apresentação dos projetos sociais desenvolvidos pela Polícia Militar;

9. espaço de divulgação de cursos e eventos;

10. seção de procurados e desaparecidos; e

11. informações sobre a estrutura da Polícia Militar.

- nível da imprensa - disponível para os veículos de comunicação (imprensa) cadastrados no Portal Corporativo. O principal objetivo é disponibilizar informação detalhada sobre todas as ocorrências na região. A disponibilização completas das ocorrências é serviço exclusivo para o nível da imprensa;

- nível interno/intranet - apenas para os policiais militares. Na intranet, o objetivo central é a difusão de informação precisa e atualizada aos diversos postos e graduações da PM, nas áreas de recursos humanos, inteligência, planejamento de operações, logística e comunicação organizacional. Os serviços disponibilizados são:

1. fornecimento das sinopses de todas as ocorrências da região;

2. agenda operacional, com a listagem das principais ocorrências que requerem a atuação da corporação, além das escalações; 
3. ensino, pois existem os cursos com acompanhamento eletrônico, disponibilizando-se material e provas;

4. mural de recados;

5. downloads de vários documentos de interesse;

6. organograma da $6^{\mathrm{a} R P M}$;

7. fórum de discussões para o debate de vários assuntos; e

8. sala de chat.

- nível administrativo - disponibilizado apenas para o pessoal responsável pela manutenção do portal e pela alimentação dos dados. O objetivo é manter o portal atualizado e garantir a veracidade das informações e dos serviços prestados.

O processo de implementação do Portal Corporativo ocorreu, num primeiro momento, pela conscientização dos atores organizacionais quanto à importância de se utilizar essa ferramenta. Paralelamente, o portal foi implementado num formato mais simplificado, quando apenas alguns dos serviços descritos anteriormente estavam disponíveis. O nível externo foi o primeiro passo e o foco era a disponibilização das ocorrências. Com isso, acredita-se que houve, de imediato, uma reação ao mesmo tempo positiva e negativa por parte dos policiais militares. Positiva, pois estavam interagindo mais intensamente com a comunidade. Negativa, pela iminente ameaça de quebra das barreiras da informação policial. Tais aspectos serão retomados para análise, posteriormente. Por enquanto, o que vale ressaltar é que diante dessa reação, surgiu a necessidade de "aprender" novas formas de relacionamento com a comunidade e, até mesmo, de "aprender" a manipular as informações de forma mais segura ante a TI implementada. Diante disso, o que segue são etapas de treinamentos, que não aconteceram de maneira formalizada ou massificada; ou seja, os treinamentos fluíram conforme as necessidades e dificuldades de cada indivíduo ou de determinado grupo. Isso também propiciou uma maior interação entre os policiais e uma visão mais "amigável" da utilização do Portal Corporativo.

A implementação do Portal Corporativo da $6^{\mathrm{a}}$ RPM foi quase contínua, uma vez que as melhorias incluem novas ferramentas. Nesse contexto, de acordo com o capitão da $6^{\underline{a}} \mathrm{RPM}$, o processo de aprendizagem também é contínuo e as mudanças são compartilhadas entre indivíduos, grupos; conseqüentemente, atingindo a organização. É nesse sentido que o processo de implementação e utilização do Portal Corporativo apresenta relações com os níveis culturais e de poder estabelecidos entre os membros da organização.

\section{Portal Corporativo, cultura e relações de poder na Polícia Militar}

Para apreender os significados compartilhados entre os atores organizacionais, foram realizadas 13 entrevistas (via questionário não-estruturado) com policiais militares da $6^{\mathrm{a}} \mathrm{RPM}$. Os entrevistados não foram escolhidos aleatoriamente, pois o objetivo era ter um conjunto de respondentes o mais amplo e representativo possível da estrutura da corporação. Para isso, foram ouvidos representantes dos mais diversos postos (soldado, cabo, sargento, subtenente, tenente, capitão, major, tenente coronel, coronel), em funções administrativas e operacionais, homens e mulheres. Além disso, também foi realizada uma entrevista com o capitão da $6^{\mathrm{a}}$ RPM, uma análise detalhada dos textos e discursos ("Mural de Recados" e "Fórum de Discussão) disponíveis no Portal Corporativo e a observação não-participante, por meio de visitas periódicas realizadas pelos pesquisadores. Esse conjunto de informações possibilitou levantar a percepção que os policiais militares têm a respeito do Portal Corporativo, bem como permitiu visualizar as interações entre essas percepções, a cultura e as relações de poder.

Por meio da percepção dos membros organizacionais privilegiou-se a dimensão simbólica como expressão de realidade. Dessa forma, a organização militar foi considerada uma realidade socialmente construída, produto da criação coletiva dos sentidos e significados atribuídos pelos policiais diante da implementação da TI. Por isso, foi possível analisar e discutir as relações da TI com a cultura e as relações de poder, considerando a organização como um espaço de elaboração e negociação de princípios, envolvendo os processos de articulação de interesses entre os membros organizacionais. Foram justamente os questionamentos que surgiram acerca da inova- 
ção tecnológica que impulsionaram algumas mudanças, mesmo que a nível ideológico, sobre a estrutura de poder na organização militar.

As análises dos relatos revelaram, num primeiro momento, as idéias compartilhadas acerca da própria organização e os significados a respeito do trabalho militar. Ficou evidente que a organização militar é dotada de significados, como o dever público de garantir a segurança, a representação de um corpo (o corpo da organização, o pessoal) dotado de força para tal, a idéia de um campo organizacional legitimado socialmente e a noção de uma identidade organizacional homogênea, bastante característica que é a identidade militar.

A prestação de serviços à comunidade - nesse caso, o dever de protegê-la de atitudes criminosas - foi a percepção mais recorrente entre os policiais entrevistados. Para os atores organizacionais, a missão de uma organização militar diferencia-se de outras missões ou objetivos organizacionais na medida em que mesma (já difundida na organização) tem no seu próprio conteúdo, o objetivo do trabalho diário dos policiais. Portanto, o compromisso da organização é o compromisso de cada um de seus membros, fato que reforça a noção de força tão compartilhada entre os militares; força não apenas no aspecto físico, mas também em termos da capacidade de unificação da vontades e dos valores de cada um. Visto que, se o objetivo organizacional é também o de todos, não existe o trabalho individual, mas sempre a atividade coletiva.

Ao mobilizar forças coletivas para garantir a eficiência de suas atividades, a organização militar conta também com o apoio da comunidade em geral. Assim, dois extremos devem estar em sintonia: a corporação, cumprindo o seu papel (missão militar), e a comunidade, preparando o palco para sua atuação (a atividade dos militares). Conforme os discursos dos policiais, a organização militar é sempre sustentada pela legitimidade de suas atividades no campo social de atuação; é, portanto, uma organização legitimada socialmente.

Justamente por tal característica é que esse tipo de organização possui uma forte identidade constituída e compartilhada que caracteriza o trabalho de seus membros. Foi observado que o trabalho militar é percebido por seus executores como um trabalho dotado de poder. É preciso ter cautela ao mencionar o poder no trabalho da Polícia Militar. O significado do trabalho atrelado ao poder emerge no sentido de poder/dever; ou seja, é preciso que seja dado poder ao militar para que ele cumpra sua missão de garantir a segurança pública. Dessa forma, ele tem "direitos" garantidos apenas para a condição de militar, que não são extensivos à condição de civil. O poder para cumprir as atividades é ensinado, internalizado e disseminado na organização. Porém, quando é utilizado de forma abusiva, pode acarretar danos para a imagem organizacional e enfraquecer uma das características culturais da organização militar: a legitimidade social.

Esse fato se revela como uma das preocupações dos atores organizacionais, os quais contestam a generalização da imagem da PM associada a abuso de poder:

[...] A verdade é clara. Nossa instituição é séria e eficiente, e possui funcionários dedicados e exemplares, devido ao profissionalismo e postura mantidos perante uma sociedade tão questionadora e desigual. (trecho de discurso de policial militar presente no fórum de debates do Portal Corporativo da $\sigma^{\underline{a}}$ $R P M)$

Nesse contexto, a disciplina surge como elemento central que garante o comportamento "esperado" de um policial. O trabalho militar é repleto de regras de conduta e procedimentos padronizados e que implicam certa constância. Dessa forma, a organização militar, ao mesmo tempo em que depende da legitimidade da comunidade, também mantém uma distância da mesma. Isso ocorre pois, no cumprimento das regras de conduta e dos procedimentos militares, e através de um processo rígido de socialização, os membros da organização acabam por "despojar" o civil e "vestir" o militar, conforme demonstram Brito e Brito (1996).

As considerações apresentadas remetem à idéia de que, numa organização militar, os membros compartilham de uma identidade ideológica consistente, caracterizada pela disciplina, pelo poder, pela legitimação de suas atividades e por uma missão. O reforço da identidade ocorre por meio de simbologias como a própria hierarquia, representada nos uniformes etc., nos rituais de admissão, na socialização, nos treinamentos militares, palestras, reuniões, etc.; e, os mitos, as estórias e memórias referentes à própria organização e sua trajetória, bem como de seus heróis. Portanto, trata-se de uma organização de cultura fortemente compartilhada entre seus 
membros. Nesse cenário, como seria possível a implementação de processos como a TI, os quais requerem algumas mudanças nos próprios processos culturais e nas relações de poder?

Pôde-se observar, particularmente na $6^{\mathrm{a}} \mathrm{RPM}$, uma maior abertura para processos inovadores, como a adoção de TI. A despeito das características apontadas anteriormente e de ser percebida por seus membros como uma organização de regras e padrões de conduta rígidos, a organização em questão também é vista como flexível. No entendimento dos entrevistados, tal flexibilidade é impulsionada pelo estilo de administrar característico de alguns policiais do setor administrativo, os quais procuram enfatizar uma visão mais sistêmica e inovadora. Foi assim, a partir dessa abertura, que surgiu a idéia de um núcleo de projetos e a parceria com a Universidade Federal de Lavras, propiciando uma maior abertura, com a visão de alunos e professores universitários. Essa visão, associada à formação do núcleo de projetos, viabilizou a implementação do Portal Corporativo da $6^{\underline{a}}$ RPM.

Anteriormente, foram descritos os passos para a implementação e as principais características do portal. Com o processo de implementação do Portal Corporativo da $6^{\mathrm{a}} \mathrm{RPM}$, os policiais passaram a dispor de uma ferramenta que poderia impulsionar mudanças, não apenas operacionais, mas também gerenciais. Essas mudanças, por sua vez, são da ordem dos fenômenos que envolvem, principalmente, os processos de comunicação dos atores organizacionais.

No caso da 6 $6^{\mathrm{a}}$ RPM, a comunicação ocorria, antes da implementação do Portal Corporativo, por meio de ofícios e outros processos que, muitas vezes, dificultavam a efetividade do fluxo de informações e até reforçavam padrões de rigidez na organização militar. Diante de uma ferramenta que, possivelmente, "desburocratizaria" o processo de comunicação e facilitaria o fluxo de informações, também surgiram questionamentos quanto a essa ferramenta, como por exemplo, se sua implementação não iria desestruturar a "hierarquia", ainda que no plano simbólico, da organização. Por isso, a importância de um processo de conscientização sobre o uso da TI, antes de sua implementação.

Na fase de conscientização dos policiais para a importância da mudança e do uso dessa ferramenta, um dos objetivos era disseminar o conceito do Portal Corporativo entre os membros da organização. De acordo com um capitão da $6^{\mathrm{a}} \mathrm{RPM}$, muitos policiais mantinham uma noção superficial do que seria o portal e sobre como ele poderia ser útil no trabalho da Polícia Militar. Pelos discursos dos entrevistados - os quais já utilizam o portal em seu trabalho -, pôde-se perceber uma idéia mais consolidada acerca do conceito e da função dessa ferramenta:

O Portal Corporativo é uma ferramenta que divulga as informações da PMMG, aproximando o público interno (os profissionais que fazem segurança publica) e dando espaço também ao público externo (os clientes), para conhecer a instituição e até para se manifestar. (discurso de um capitão)

O Portal Corporativo é mais um instrumento para auxiliar nas ações, operações, comunicação dos militares. É a informática utilizada em prol da segurança. Essa ferramenta pode auxiliar no meu trabalho, pois a informação, em qualquer setor, é a responsável pelo sucesso de uma pessoa ou empresa. O portal, além de informar, facilita a comunicação; há como diminuir dúvidas de maneira mais rápida." (discurso de um Sargento)

É possível observar alguns significados associados ao portal, como a facilidade de comunicação e a interação com a comunidade. Essa interação ocorre por meio do nível externo disponibilizado no Portal Corporativo. O nível interno é percebido pelos policiais, principalmente, como facilitador da comunicação interna e aproximador das relações, possibilitando uma maior participação dos atores organizacionais, de uma maneira geral, nas decisões da organização militar. Esse processo de participação, antes da implementação do Portal Corporativo, ocorria limitado pelos procedimentos formais pelos quais os policiais encaminhavam suas sugestões. Depois da implementação do portal, as sugestões puderam ser encaminhadas a qualquer momento, estando disponíveis para a visualização geral, o que facilita a participação de outros policiais, por exemplo, no incremento das idéias. Trata-se de um incentivo para a participação nos processos organizacionais que acaba sendo compartilhado entre os membros da organização.

Evidencia-se um processo de mudança no que tange às relações de poder estabelecidas entre os membros organizacionais. Como já mencionado, a organização militar caracteriza-se por uma estrutura hierárquica rígida e 
por regras de conduta e procedimento bastante consolidados. No entanto, ao implantar um canal de comunicação que possibilite o acesso direto entre os policiais, em qualquer nível de graduação ou posto, o Portal Corporativo permite a aproximação e, de certa forma, o achatamento dessa hierarquia, mesmo que se verifique no plano da comunicação, e não no plano estrutural. Observe-se alguns diálogos que ocorrem via portal:

De cabo para tenente: sr. tenente A. O sr. sabia que em 1949, só se falava de uma coisa na cidadezinha de Ituverava, no interior de São Paulo...

Resposta: parabéns, cabo B, vejo que você é um pesquisador...

(diálogo entre um cabo e um tenente no Fórum de Debates do Portal Corporativo - nível interno)

De tenente para major: sr. major, bom dia!! Estou formatando o material a ser utilizado na divulgação virtual. Tive uma idéia de estarmos realizando o nosso primeiro estágio virtual de qualificação...

Resposta: caro companheiro, esse projeto será muito importante para todos nós, e, principalmente, para a comunidade na qual estamos também inseridos...

(diálogo entre um tenente e um major no Mural de Recados do Portal Corporativo - nível interno).

Evidentemente, a hierarquia continua a mesma em termos de distribuição de funções e postos. Porém, o achatamento ocorre pela comunicação e pela possibilidade de negociação de interesses entre os membros organizacionais. Se para Foucault (1977) o poder é relacional e independe de sua posse, pode-se afirmar que as relações na $6^{\mathrm{a}} \mathrm{RPM}$, mesmo entre postos diferentes, tentam negociar interesses e idéias, numa hierarquia formal não necessariamente visível, mas que existe. Isso significa que com a utilização do Portal Corporativo, as relações de poder se modificam e abre-se espaço para a negociação e a participação de policiais, por meio de sugestões e do debate de idéias. Dessas relações, surgem propostas e novas formas de relacionamento, tornando o processo um aprendizado contínuo.

Além disso, o discurso dos entrevistados revela mudanças nas relações quanto à distribuição de responsabilidades, às interações comunicativas e às reformulações de idéias. As responsabilidades se tornam menos centralizadas, como por exemplo no caso do repasse das ocorrências. Ao invés de um policial ser o responsável, todos que tiverem acesso devem disponibilizar via portal. Desse modo, a responsabilidade recai sobre o próprio indivíduo, que, dotado de saber/dever (competência para disponibilizar informações no portal e dever de fazê-lo) tem sua função interligada e dependente das demais funções. Portanto, cada membro é peça fundamental para a fluência e eficiência das informações repassadas, pois um dado disponibilizado de maneira incorreta, impossibilita a articulação de outras funções, e assim sucessivamente. Nesse sentido, o poder está muito mais na responsabilidade atribuída ao membro da organização do que no posto que ele ocupa.

Assim, observa-se que a concepção de poder adotada nesta pesquisa, contribui para as análises das relações de poder estabelecidas com a implementação da TI em uma organização militar. Verifica-se que o poder, com o uso do Portal Corporativo, depende muito mais da troca de informações e da maneira como essa troca ocorre, do que do posicionamento ocupado na organização. Trata-se de privilegiar o espaço de "negociação de interesses" e, mediante a criação desse espaço, distribuir responsabilidades e, conseqüentemente, recompensas.

Com o canal de comunicação intensificado pelo Portal Corporativo e a emergência de idéias e significados compartilhados entre os policiais, além da interação com a comunidade, ressalta-se a emergência de novos valores, crenças e símbolos acerca da organização e do próprio trabalho militar. Nos relatos, fica evidente um processo de reformulação ideológica que, conseqüentemente, levará a um processo de compartilhamento de novas crenças, as quais podem estar sinalizando um processo de mudança cultural em curso.

Resistências aos novos valores surgidos no processo de inovação existem, e estão presentes nos discursos. Porém, percebe-se que as forças resistentes existem pelo ainda pouco conhecimento de muitos policiais acerca de ferramentas computacionais e das vantagens da Internet para o fluxo de informações. Por outro lado, os relatos também revelaram que tais dificuldades encontram-se, principalmente, entre os policiais de função operacional, 
devido a fatores como: falta de tempo para acessar o Portal Corporativo e resistência a lidar com recursos de informática. Além disso, as análises também revelaram a necessidade de se atentar para uma maior integração entre os militares operacionais e administrativos, a fim de que estes repassem informações acerca do Portal Corporativo para aqueles:

[...] há que se trabalhar com esses militares (operacionais), demonstrando a eles a importância da informática nos dias atuais. Há como realizar um trabalho efetivo com os militares, através da utilização de um laboratório e cursos para que eles aprendam e visualizem a importância de entrar para o mundo virtual. (discurso de um sargento)

Entretanto, mesmo diante de dificuldades advindas, principalmente, de uma cultura fortemente enraizada, observa-se um movimento de mudança dos valores compartilhados entre os policiais militares. Ao traçar um paralelo entre o antes e o depois da implementação do Portal Corporativo, por meio de uma tabela apresentada contendo elementos e níveis numéricos a serem indicados, os entrevistados revelaram que o nível de elementos como "inovação", "trabalho em equipe" e "participação e informação" apresentou-se elevado após a implementação da TI. Quanto à burocracia e à hierarquia (informal), observou-se uma queda após o Portal Corporativo. Os elementos subjetivos que sustentam tais mudanças podem ser compreendidos a partir dos movimentos de internalização e compartilhamento de valores, expressos por meio dos símbolos, rituais e mitos. Esse processo, conforme revelam as análises, sofre forte impacto com o uso da TI (o Portal Corporativo), ao lançar novas simbologias e significados.

Os símbolos, rituais e mitos adotados na organização com a implementação do Portal Corporativo podem ser descritos da seguinte maneira:

- os símbolos da inovação - representados pelo próprio Portal Corporativo, pelo aparato tecnológico envolvido e por outros projetos da organização. A comunidade passa a reformular a imagem que tem da organização militar, pela maior aproximação com o trabalho militar via portal;

- os rituais da aprendizagem, da flexibilidade e da negociação - vivenciados em treinamentos mais flexíveis, agregando maior responsabilidade ao próprio policial de buscar o seu conhecimento. Paralelamente, nos espaços para debates e troca de idéias do portal, verificam-se os rituais de negociação de interesses e de compartilhamento de conhecimento, obscurecendo a hierarquia formal da organização;

- os mitos dos inovadores e outras organizações como referência - o deslocamento de uma referenciação basicamente de caráter militar, para a recuperação de histórias e heróis provenientes de outros campos, como, por exemplo, a universidade. Também os agentes da mudança e da inovação, como aqueles pioneiros no projeto do Portal Corporativo, passam a servir como referência para a construção de uma nova identidade que será compartilhada no processo de reformulação cultural.

Com isso, vale ressaltar que através da reformulação de alguns elementos constitutivos da cultura organizacional - por meio da linguagem e impulsionada pela utilização da TI - foi possível compreender como esse processo de inovação pode influenciar na definição e objetivação das crenças organizacionais. Essa constatação vai ao encontro das idéias de Schultz (1994); ou seja, ao considerar a comunicação entre os processos como importante fator para manter a realidade simbólica compartilhada, evidencia-se que a implementação da TI facilita o compartilhamento das crenças e, portanto, da realidade organizacional.

Por meio das análises, delineou-se o caminho percorrido para a reformulação da "teia de significados" entre os membros organizacionais. Foi constatado que o ambiente competitivo impulsiona as organizações para a mudança. No caso da $6^{a}$ RPM, a mudança é representada pela adoção da TI, o Portal Corporativo que foi estendido a toda a organização.

Ao implementar a tecnologia no trabalho militar, o sistema cultural e as relações de poder características de organizações militares mais tradicionais, começam a sinalizar para a presença de valores mais flexíveis e inovadores, que passam a ser compartilhados entre os policiais. Tais valores transcendem as barreiras da organização e atingem a comunidade em geral, constituindo um processo de legitimação. Esse processo não pode ser entendido como inacabado, visto que novamente a organização será chamada à mudança e novos valores, símbolos e crenças serão compartilhados entre os membros organizacionais. 


\section{Considerações finais}

Por meio deste artigo objetivou-se analisar a relação entre a adoção da tecnologia da informação (Portal Corporativo), a cultura e as relações de poder numa organização de caráter militar. Para tanto, foi empregado o conceito de TI como inovação tecnológica atrelado aos conceitos de cultura e poder nas organizações. A abordagem da cultura adotada nesta pesquisa é a interpretativa, podendo constituir-se de estruturas inconscientes, símbolos e significados compartilhados. Portanto, privilegiou-se a dimensão simbólica nas análises, assim como os rituais, mitos e símbolos culturais. Ao adotar um elemento de mudança, a TI, a organização necessita legitimar a nova ordem o que pode causar impacto nas relações entre os atores sociais e grupos.

A metodologia de análise foi o estudo de caso na $6^{\underline{a}}$ Região da Policial Militar de Minas Gerais, na cidade de Lavras, sob o paradigma interpretativo, por meio da análise qualitativa, procurando avaliar a interação entre o indivíduo e o contexto social. Deve ser ressaltado que este estudo não centrou seu interesse no conteúdo formal das relações ou da utilização do Portal Corporativo, e sim na subjetividade dos policiais. Buscando resultados exploratórios, devido ao número reduzido de pesquisas dessa natureza, empregou-se a triangulação na coleta de dados.

Com base nessa fundamentação teórico-metodológica, permitiu-se que nas análises empreendidas nesta pesquisa fosse considerada a subjetividade compartilhada pelos membros da organização militar em torno da implementação do Portal Corporativo da $6{ }^{a}$ RPM. Nesse sentido, a caracterização da organização e a compreensão do processo de implementação do portal auxiliaram nas análises e evidenciaram características próprias da organização militar.

Observou-se que a organização militar, por ter uma missão definida e uma estrutura interna rígida e legitimada entre os membros organizacionais, enfrenta uma "limitação" para a implementação de processos tidos como inovadores. Isso fica evidenciado pela própria "socialização organizacional", que visa internalizar as normas, valores e comportamentos apropriados à cultura militar. Esses fatores indicam uma cultura que pode dificultar processos de mudança e inovação. Entretanto, verificou-se que, na organização estudada prevalece a "visão para a mudança", o que, de certa forma, possibilitou dar início à implementação do Portal Corporativo.

A "visão voltada para a mudança" apresentou-se como resultado do compartilhamento entre os policiais da organização militar, uma organização inserida num contexto em que dependente de "estratégias" para sua sobreviver e manter a qualidade com que exerce suas funções. A partir de então, a $6^{\mathrm{a}}$ RPM começou a estabelecer parcerias com universidades e órgão de pesquisa, para o desenvolvimento de novas tecnologias. Dessa forma, a despeito de uma forte identidade constituída e compartilhada - que caracteriza o trabalho dos policiais militares - constatou-se que a "visão para a mudança" pode propiciar um canal para a implementação de novas tecnologias em organizações militares. Portanto, a recuperação das características da organização em estudo contribuiu para a compreensão das mudanças em torno da cultura organizacional e das relações de poder, em face da implementação e uso da TI.

Verificou-se que a cultura é reformulada a partir da mudança advinda de um ambiente competitivo. No caso da organização em estudo, a mudança é representada pela adoção da TI, o Portal Corporativo, o qual foi estendido a toda a $6^{\mathrm{a}}$ RPM. Pôde-se apreender que a implementação da TI necessita do comprometimento dos membros organizacionais. Por isso, a disseminação dos conceitos da TI entre os policiais, por meio do Portal Corporativo, foi de fundamental para o desenvolvimento de suas atividades. Além disso, o compartilhamento das informações sobre o portal propiciou o fluxo de aprendizagem e, portanto, de mudança cultural.

Implementada a tecnologia no trabalho militar, o sistema cultural e as relações de poder características de organizações militares mais tradicionais começam a sinalizar a presença de valores mais flexíveis e inovadores, que passam a ser compartilhados entre os policiais. Foi constatado que na organização estudada, esse compartilhamento é contínuo, mediante as constantes melhorias implementadas no Portal Corporativo. Por isso, ao disseminar novos conhecimentos entre indivíduos, grupos e organização, o processo de implementação e utilização do Portal Corporativo causa impacto na cultura e nas relações de poder estabelecidas entre os membros organizacionais. 
Por meio das análises ficaram evidenciadas as idéias compartidas sobre a própria organização e os significados sobre o trabalho militar. O significado do dever público de garantir a segurança, a representação de um corpo (o corpo da organização, o pessoal) dotado de força para tal, a idéia de um campo organizacional legitimado socialmente e a noção de uma identidade organizacional homogênea - bastante característica da identidade militar - contribuíram para a compreensão do impacto causado pela TI na cultura e nas relações de poder da Polícia Militar.

Nesse processo, os símbolos físicos, os rituais e os mitos tiveram um importante papel para as análises. Observou-se a utilização dos símbolos da inovação, como o próprio Portal Corporativo, como ferramenta para reformular a imagem da organização militar. Os rituais verificados após a implementação da TI giram em torno da aprendizagem, da flexibilidade e da negociação, como os treinamentos voltados para o compartilhamento de conhecimento, obscurecendo a hierarquia formal da organização. Também foi constatada a presença dos mitos dos inovadores e de outras organizações como referência para o deslocamento de uma referenciação basicamente de caráter militar, em prol da mudança. Nesse contexto, os agentes da mudança e da inovação, como aqueles pioneiros no projeto do Portal Corporativo, serviram como referência para a construção de uma nova identidade compartilhada no processo de reformulação cultural.

A análise da utilização do Portal Corporativo também revelou mudanças nas relações de poder, na medida em que tal utilização abre espaço para a negociação e para a participação de policiais, por meio de sugestões e debates de idéias. Dessas relações surgem propostas e novas formas de relacionamentos, tornando o processo um aprendizado contínuo. Além disso, os discursos dos entrevistados revelaram mudanças nas relações quanto à distribuição de responsabilidades, às interações comunicativas e às reformulações de idéias. As responsabilidades se tornam menos centralizadas e recaem sobre o próprio indivíduo; ou seja, cada membro é peça fundamental para a fluência e eficiência das informações repassadas. Nesse sentido, o poder está muito mais na responsabilidade atribuída ao membro da organização do que no posto que ele ocupa.

Com isso, ressalta-se a emergência de novos valores, crenças e símbolos acerca da organização e do próprio trabalho militar. Nos relatos, evidenciou-se um processo de reformulação ideológica que, conseqüentemente, levará a um processo de compartilhamento e reformulação da cultura. Pode-se dizer que essa mudança ocorre em nível ideológico, visto que, em termos de hierarquia, esta continua a mesma quanto à distribuição de funções e postos. O que muda é a comunicação e a possibilidade de negociação de interesses entre os membros da organização militar; ou seja, com a utilização do Portal Corporativo, abre-se espaço para a negociação e para a participação de policiais.

Por conseguinte, constatou-se a necessidade da organização viabilizar, por meio de técnicas pedagógicas (formais ou informais), a integração dos policiais ao processo de implementação e uso do Portal Corporativo. Essa necessidade resulta do entendimento de que o membro organizacional atuará mais conscientemente se incorporar os princípios propostos pela organização.

A fundamentação deste estudo, que incorporou tanto reflexões dos policiais como análises teóricometodológicas, não tem sido muito adotada nos trabalhos científicos, especialmente, no que tange à questão da TI. Acredita-se que o trabalho impulsione a realização de outras pesquisas voltadas para estudos mais reflexivos de fenômenos organizacionais como a inovação, contribuindo como fonte de subsídio para as melhorias e mudanças nas organizações.

\section{Referências}

AKTOUF, 0. 0 simbolismo e a cultura de empresa: dos abusos conceituais às ligações empíricas. In: CHANLAT, J. F. (Org.). 0 indivíduo nas organizações. São Paulo: Atlas, 1993.

ALENCAR, E. Introdução à metodologia de pesquisa social. Lavras: UFLA, 1999.

BORNSTEIN, C. T.; VILLELA, P.R.C. 0 uso da informática em cooperativas de laticínio: algumas reflexões sobre a modernização na agricultura. Reforma Agrária, v.3, n.4, p.53-73, set./dez., 1992.

BRITO, M. J.; BRITO, V.G. P. Socialização organizacional: a iniciação na cultura militar. Revista de Administração Pública: FGV, Rio de Janeiro, p.138-65, jul./ago. 1996. 
DRUCKER, P. Innovation and entrepreneurship. New York: Harper Perennial, 1986.

FLEURY, A.; FLEURY, M.T.L. Aprendizagem e inovações organizacionais: as experiências de Japão, Coréia e Brasil. São Paulo: Atlas, 1995. FOUCAULT, M. Discipline and punish: the birth of the prison. Harmondsworth: Penguin, 1977.

FREITAS, M. E. Cultura organizacional: grandes temas em debate. Revista de Administração de Empresas, São Paulo, v.31, n.3, p.73-82, jul./set. 1991.

GEERTZ, C. A interpretação das culturas. Rio de Janeiro: LTC, 1989.

HARDY, C.; CLEGG, S. R. Alguns ousam chamá-lo de poder. In: CLEGG, S. R.; HARDY, C.; NORD, R. Handbook de Estudos Organizacionais: reflexões e novas direções. São Paulo: Atlas, 2001.

LAURINDO, F. J. B. et al. 0 papel da tecnologia da informação (TI) na estratégia das organizações. Gestão e Produção, São Carlos, v.8, n.2, p.160-179, ago. 2001.

MARTIN, J. Cultures in organizations. Oxford: Oxford University Press, 1992.

MARX, K. Capital. Harmondsworth: Penguin, 1976.

MUNFORD, E. El diseño participativo de sistemas: práctica e teoria. In: LA AUTOMATIZATION y el futuro del trabajo. Espanha: Ministerio del Trabajo y Seguridad Social, 1988.

MURRAY, D. J. Case study as form of enquiry. In: THE OPEN university. Social sciences. London: The Open University, 1974. p.165-172.

PORTER, M. E. Vantagem competitiva: criando e sustentando um desempenho superior. 17 ed. Rio de Janeiro: Campus, 1989.

PRATES, G. A.; OSPINA, M. T. Tecnologia da informação em pequenas empresas: fatores e êxito, restrições e benefícios. Revista de Administração Contemporânea: Anpad, Rio de Janeiro, v.8, n.2, abr./jun. 2004.

SCHEIN, E. H. Culture: the missing concept in organization studies. Administrative Science Quarterly, v.41, p.229-240, 1996.

SCHULTZ, M. On studying organizational culture: diagnosis and understanding. New York: Gruyter, 1994. p. 75-148.

SCHUMPETER, J. Capitalism, socialism and democracy. New York: Harper Perennial. 1975.

Teoria do desenvolvimento econômico. São Paulo: Abril, 1982.

SCHUTZ, A. Fenomenologia e relações sociais. Rio de Janeiro: Zahar, 1979.

SEGRE, L. M.; XEXEO, J. A. M. Informatização em empresas sob um enfoque de modelagem social da tecnologia. Rio de Janeiro: Coppe/UFRJ, 1995.

STONER, J. A.F. Administração. 5. ed.Rio de Janeiro: LTC, 1999.

THOMPSON, J. D. Authority and power in identical organizations. American Journal of Sociology, p. 290-301, 1956.

TRIVIÑOS, A. N. S. Introdução à pesquisa em ciências sociais: a pesquisa qualitativa em educação. São Paulo: Atlas, 1987. 175p.

WEBER, M. Economy and society: in outline of interpretive sociology. Berkeley, CA: University of California Press, 1978. v. 2. 